\title{
Interactive Session on 'Focus Group Discussion' for Health Professionals in India: A Mixed-Methods Evaluation
}

\author{
Dongre, A.R. ${ }^{1}$, Kalaiselvan, ${ }^{2}{ }^{2}$
}

\begin{abstract}
Objective: To design an interactive session on Focus Group Discussion (FGD) and evaluate it from the participants' view point.

Methodology: Study setting was a five-day long workshop on 'Qualitative Research Methods' for health professionals, with 30 health professionals from 8 different states of India having public health, clinical and nursing backgrounds as participants. A mixed-methods design of triangulation type was utilized, where both quantitative (Likert type feedback and retro-pre survey) and qualitative (data emerging during group work) data was simultaneously collected and analyzed. After a brief sensitization on FGD guidelines, 30 participants were divided into two equal groups. Participants were given a group work on planning and running an FGD. We used 'Fishbowl' seating arrangement to take them through the FGD process and experience the role of facilitator and the role of participant. It was followed by a debrief. Content analysis of qualitative data was done and consensus scores were calculated from the feedback responses.
\end{abstract}

Results and conclusion: The session on FGD was well received (weighted mean-1.4; consensus$81.5 \%$ ). The post-session mean score for their perceived ability to facilitate FGD increased to 4.8 from a pre-session score of $2.1 \quad(\mathrm{p}=0.009)$. The session design helped facilitate a discussion on challenges in running an FGD, such as the influence of facilitator's anxiety, mutual coordination, note-taking and seeking information from the participants and its potential effect on data quality and validity.

\section{Introduction}

Focus Group Discussion (FGD) is a group discussion among persons guided by a facilitator, during which the members of the group talk freely and spontaneously about a certain topic (Dawson et al. 1993). Over time, focus groups have evolved in terms of their scope, guidelines, style of moderation and nature of participant involvement making it increasingly confusing for the novice learners. In health and educational research, FGD is commonly used for exploration of perspectives and the development of culturally sensitive and context-specific survey instruments and interventions (Barbour, 2007).

${ }^{1}$ Professor and Head

${ }^{2}$ Professor

Department of Community Medicine,

Sri Manakula Vinayagar Medical College and Hospital,

Pondicherry, India

Corresponding Author:

Dr Amol Dongre

2Professor, Department of Community Medicine,

Sri Manakula Vinayagar Medical College and Hospital,

Pondicherry, India
Considering its rising applications, it is crucial to train health professionals in the conduct of FGDs.

Conventionally, a didactic training session on FGD techniques for novice learners may emphasize the development of FGD guidelines, its planning and implementation process, with minimal or no importance given to hands-on learning. Taking a group of learners to a local community for a hands-on exercise would be demanding in terms of required logistics and time. Use of video or tutor demonstrations for FGDs may be considered, but it would put learners in a more passive observer state. Thus, it is a challenge for a training faculty to plan an interactive session on FGD, which emphasizes the orientation of participants to important methodological considerations (Odimegwu, 2000) and ensure hands-on learning where they actively experience the entire FGD process as a 'FGD facilitator' and a 'FGD participant' for comprehensive understanding of its dynamics.

Hence, the objective of the present study was to design an interactive session on FGD and evaluate it from the participants' view point.

Email: amolrdongre@gmail.com 


\section{Methodology}

Background and setting - A five-day long workshop on 'Qualitative Research Methods' for health professionals was conducted at the Department of Community Medicine, Sri Manakula Vinayagar Medical College and Hospital, Pondicherry, India from 6-10 January, 2014.

Participants- A multidisciplinary team of 30 health professionals from 8 different states of India having public health, social science, clinical and nursing backgrounds were selected on a 'first-come-first serve' basis. Out of 30 , only three participants had previous exposure to qualitative research methods.
Design: A mixed-methods design of triangulation type was used, where both quantitative (Likert type feedback and retro-pre survey) and qualitative (data emerged during group work and discussion) data was simultaneously collected and analyzed for the evaluation (Creswell et al., 2011) (Figure 1). The quantitative data collection in evaluation focused on the learners' immediate reactions (Kirkpatrick level 1) and their perceived acquisition of knowledge and skills (Kirkpatrick level 2) (Boet et al., 2012).

The study was approved by the Research Committee and Institutional Ethics Committee of Sri Manakula Vinayagar Medical College and Hospital, Pondicherry.

Figure 1: Visual diagram of study design for evaluation

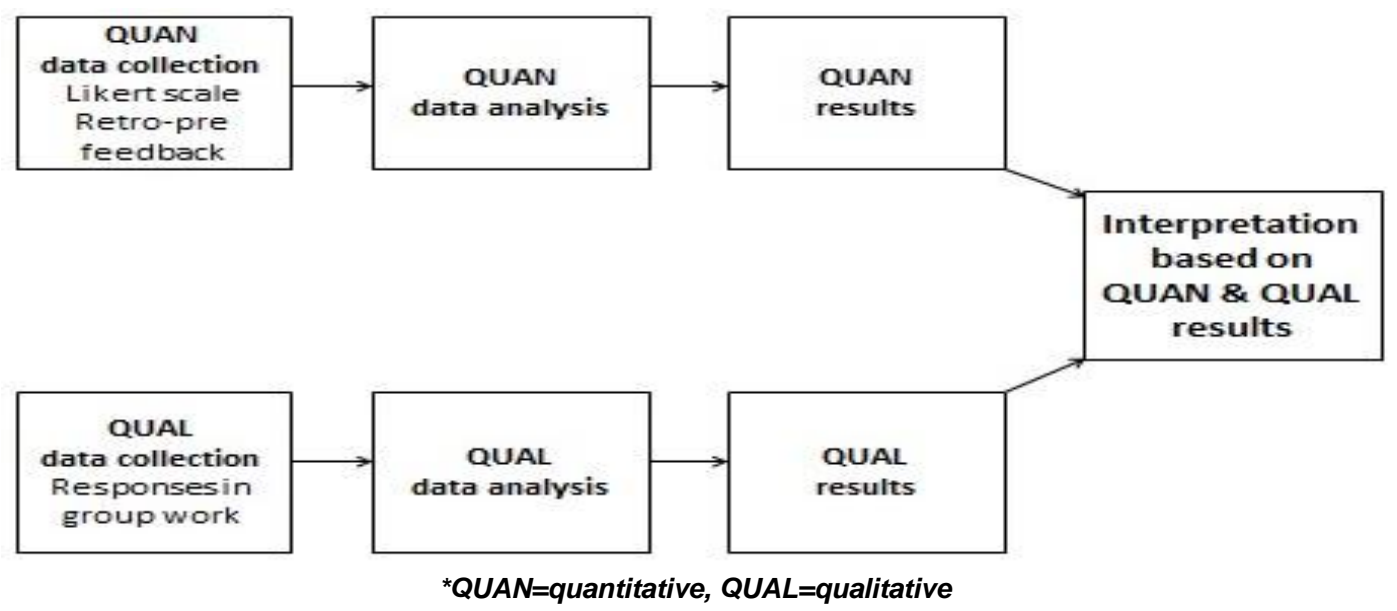

\section{Session design}

After exposure to sessions on Participatory Research Method tools and Systematic Techniques (free listing and pile sorting) on day one and two, the session on FGD was conducted on day three of the workshop. The learning objectives of the FGD session were 1) to describe steps in planning a FGD session, 2) to make participants actively experience the challenges in the conduct of a FGD.

Initially, participants were sensitized to FGD guidelines (Dawson et al. 1993). Later, 30 participants were divided into two equal major groups. Two-trained faculty supervised each major group. Each major group was again divided into two small self-managed subgroups. Each sub-group was asked to select a topic for FGD, work out an FGD interview guideline and assign the roles of moderator, note taker and observers among the group members. Two sets of 'Fishbowl' seating arrangement were done for each major group (Jaques, 2003).

Each sub-group was asked to facilitate a FGD session and the remaining sub-group members of the same major group acted as FGD participants. Facilitator, note taker and participants sat in an inner circle and the observers from a facilitating group were asked to sit in the outer circle and observe the process. After the conduct of first FGD, the roles of the sub-groups were interchanged. Thus, participants received an opportunity to experience the role of an FGD facilitator (as a team) and as an FGD participant.

In the debriefing session, participants were asked to describe their experience as a facilitator (as a team member) and as a participant. A list of experiences as a facilitator and as a participant was recorded on the white board. After a brainstorming session, participants were asked to go through a long list of points enlisted on the board. In order to 
reduce the list and prioritize the responses, they were asked to re-think to vote for the enlisted responses. They were given four stickers to vote for any two major experiences as a facilitator and any two listed experiences as participants. The total duration of the session was two and half hours.

\section{Data collection and analysis}

Feedback on the usefulness of the session was obtained by using a 'Likert' scale". Retro-pre feedback on a five-point scale was obtained for self-assessment of their perceived acquired skills. Consensus scores were calculated for the response statements and retro-pre mean scores were calculated to determine their perceived acquired skills in facilitation of FGD. Consensus measure was expressed in percentage. Those values at the upper end of the range were more in "agreement" than the values at the lower range. The value closer to 1 or $100 \%$ has less dispersion around the weighted mean value and greater agreement. Low consensus values were interpreted as having a high dispersion around a mean value (Tastle et al. 2005). We decided on an arbitrary cutoff of $60 \%$ to reflect good consensus and values below $60 \%$ to reflect poor consensus.

Content analysis of the responses emerging in the group work was done. The number in front of each statement represents the number of votes given by the participants. The compiled responses were shared with the participants for their final comments and feedback.

\section{Results}

Participants' experiences in the role of facilitator were grouped under three different categories -1) Planning - As a part of an FGD facilitation team, most participants were thinking of planning an FGD session, (designing open ended questions in FGD guidelines) and selecting a (less sensitive) topic. 2) Emotional reactions - As a facilitator, participants experienced some performance anxiety and stress to keep discussion flowing and experienced a fear of disturbances during FGD discussion. 3) Challenges- Participants felt some challenges related to note-taking, holding the group and coordinating with other team members.

In the role of FGD participants, some found it interesting and liked the encouragement by the facilitator. Some as participants were eager to speak and waiting for their turn to come whilst one participant mentioned that s $\mathrm{he}$ preferred to remain silent. There were some emotional reactions such as apprehension, anxiety, fear, difficulty in the expression of thoughts and discomfort with the topic (Table 1). Overall, the session on FGD was well received (weighted mean $=1.4$; consensus $=81.5 \%$ ) and group work further offered them better insights into the FGD process (weighted mean=1.3; consensus $=83.3 \%$ ). The post-session mean score for their perceived ability to facilitate FGD increased to 4.8 from pre-session score of 2.1 $(p=0.009)$ (Table 2).

Table 1: Experiences of the participants 'as a facilitator' and 'as a participant' in FGD session

\begin{tabular}{|c|c|}
\hline As an FGD facilitator & As an FGD participant \\
\hline Planning & Emotional reactions \\
\hline Planning FGD session-16 & Interesting-1 \\
\hline \multirow[t]{2}{*}{ Deciding the topic for FGD-2 } & Happy to contribute- 4 \\
\hline & Apprehension - 3 \\
\hline Emotional reactions during facilitation & Curious about statements made -3 \\
\hline Good experience-5 & Confused \\
\hline Anxiety to perform better as an FGD facilitator- 4 & Good experience \\
\hline $\begin{array}{l}\text { Good experience to practice in asking 'open ended' } \\
\text { question } \\
\text { Fear of disturbance-2 }\end{array}$ & $\begin{array}{l}\text { Waiting for turn to speak, eager to speak, } \\
\text { happy to share information }-9 \\
\text { Fear }-4\end{array}$ \\
\hline Stress to keep discussion flowing-7 & Hesitant -4 \\
\hline \multirow[t]{2}{*}{ Anxious about facilitation skills-2 } & Happy to be silent- 1 \\
\hline & Difficulty in expressing-4 \\
\hline Challenges during facilitation & Sensitive topic - uncomfortable \\
\hline Controlling group-2 & What facilitators want from me? - 7 \\
\hline Noting down information-1 & How to answer in a simple way? \\
\hline Difficult to open up the participants-2 & Encouragement of moderator - 9 \\
\hline \multicolumn{2}{|l|}{ Guiding other team members } \\
\hline Co-ordination with team members- 6 & \\
\hline
\end{tabular}

${ }^{*}$ Number denotes the number of participants voting per statement 
Table 2: Feedback of the participant for an FGD session

\begin{tabular}{lccccccc}
\hline \multicolumn{1}{c}{ Questions } & $\begin{array}{c}\text { Strongly } \\
\text { agree }\end{array}$ & Agree & $\begin{array}{c}\text { Neither } \\
\text { Agree nor } \\
\text { disagree }\end{array}$ & Disagree & $\begin{array}{c}\text { Strongly } \\
\text { disagree }\end{array}$ & $\begin{array}{c}\text { Weigh } \\
\text { ted } \\
\text { mean }\end{array}$ & $\begin{array}{c}\text { Conse } \\
\text { nsus } \\
(\%)^{*}\end{array}$ \\
\hline $\begin{array}{l}\text { Session for Focus Group } \\
\begin{array}{l}\text { Discussion has } \\
\text { contributed to my learning }\end{array}\end{array}$ & $18(60)$ & $12(40)$ & $0(0)$ & $0(0)$ & $0(0)$ & 1.4 & 81.50 \\
$\begin{array}{l}\text { Group work and Fishbowl } \\
\text { exercise on FGD has } \\
\text { offered me better insights }\end{array}$ & $21(70)$ & $9(30)$ & $0(0)$ & $0(0)$ & $0(0)$ & 1.3 & 83.30 \\
\hline
\end{tabular}

${ }^{\star}$ Figures in parentheses are percentages

\section{Discussion}

The session on FGD was well received by the participants. We found the above-mentioned interactive approach, which was based on adult learning principles, useful in facilitating a session on FGD. Participants received handson exposure in development of topic guides, running an FGD and teamwork. Lack of preparation, piloting and refinement of topic guidelines for FGD leads to suboptimal qualitative research (Barbour, 2007). It was Noteworthy that the multidisciplinary nature of the participants ensured cross-learning among participants during the group activity and finally enriched the discussion.

In our previous workshops, participants were takn to a nearby community field area for the conduct of FDDG. Even though it was an ideal approach, we had to discontinue it due to problems such as time constraints, difficulties in putting novice learners in a real-life situation, seeking community member's co-operation, and being unfamiliar with the regional language and thus assumed a passive observer state. The approach to FGD sessions in the present study addressed the above constraints as the groups of learners assumed the role of FGD facilitator and FGD participants. It was able to bring all learners in to an active position and made them experience both the role of the facilitator and the role of participants.

This session offered us a unique opportunity to explore and facilitate the discussion on the various factors operating at the level of facilitators and participants which have a potential to affect the quality and validity of the collected FGD data. To address the apprehensions of both facilitator and participants, it is recommended to start an FGD session with an icebreaker and use some structured exercises such as a free list, and pile sort to facilitate discussion and keep it focused. It has been suggested to make participants comfortable as an opening activity and the use of a 'mini-discussion', a kind of think-pair-share on a given topic. Participants may be given an opportunity to review the pre-designed questions prior to the start of the actual FGD and allow some time to frame their responses (Satterfield, 2002).

In conclusion, the overall session plan and fishbowl arrangement helped us to put the participants in an active state of learning and experience the FGD process as facilitators and participants. This interactive design on FGD helped us bring to the surface issues in planning and running focus groups and generate a discussion on it. It also helped us to facilitate a discussion on challenges such as the influence of facilitator's anxiety, mutual coordination, note-taking and keeping the discussion in flow and its potential effect on data quality and validity. In the future, we expect this session would influence the behavior of the participants as an FGD facilitator in a real-life setting. The findings of the present study would help us to refine this session in future workshops and may be useful to those who wish to facilitate similar training sessions on FGD at their workplace.

Conflict of interest: None to declare

Financial support: None

\section{References}

Barbour, S. (2007) Doing Focus Groups (1 $1^{\text {st }} \mathrm{Ed}$ ) London: SAGE publications Limited, pp.15-28.

Boet, S., Sharma, S., Goldman, J. \& Reeves, S. (2012) Medical Education Research: an overview of methods, Canadian Journal of Anesthesiology, 59, pp.159-170.

Creswell, J.W., Vicki, L. \& Clark, P. (2011) Designing and Conducting Mixed Methods Research, $\left(2^{\text {nd }}\right.$ Ed) New Delhi: Sage Publications, p.63. 
Dawson, S., Manderson, L., Tallo, V.L. (1993) A manual for the use of Focus Groups [Online] Available at http://whqlibdoc.who.int/p ublications/1993/0963552228.pdf [Accessed 27 January 2014].

Jaques, D. (2003) Teaching small groups, British Medical Journal, 236, pp. 492-494.

Odimegwu, C.O. (2000) Methodological issues in use of Focus Group Discussion as a data collection tool, Journal of Social Sciences, 4, 2-3, pp. 207-212.
Satterfield, T.R. (2002) Conducting effective Focus Groups [Online] Available at: http://www.luc.edu $/ \mathrm{hr} / \mathrm{pdfs} /$ SHRMCONDUCTING EFFECTIVE FOC US_GROUPS.pdf [Accessed 27 January 2014].

Tastle, W.J., Russell, J., Wierman, M.J. (2005) A new measure to analyze student performance using the Likert scale [Online] Available at: http://isedj.org/6/35/ISEDJ.6(35). Tastle.pdf [Accessed 27 January 2014]. 